\title{
OPEN High hydrostatic pressure shapes the development and production of secondary metabolites of Mariana Trench sediment fungi
}

\author{
Qingqing Peng, Yongqi Li, Ludan Deng, Jiasong Fang \& Xi Yu
}

The hadal biosphere is one of the least understood ecosystems on our planet. Recent studies have revealed diverse and active communities of prokaryotes in hadal sediment. However, there have been few studies on fungi in hadal sediment. Here we report the first isolation and cultivation of 8 fungi from the Mariana Trench sediment. The individual colonies were isolated and identified as Stemphylium sp., Cladosporium sp., Arthrinium sp., Fusarium sp., Alternaria sp., and Aspergillus sp. High hydrostatic pressure (HHP) test was carried out to identify the piezophily of these hadal fungi. Among them, 7 out of the 8 fungal isolates exhibited the ability of germination after incubation under $40 \mathrm{MPa}$ for 7 days. Vegetative growth of the isolates was also affected by HHP. Characterization of secondary metabolites under different pressure conditions was also performed. The production of secondary metabolites was affected by the HHP treatment, improving the potential of discovering novel natural products from hadal fungi. The antibacterial assay revealed the potential of discovering novel natural products. Our results suggest that fungal growth pressure plays an important role in the development and production of secondary metabolites of these hadal fungi under the extreme environment in the Mariana Trench.

The hadal zone, comprised mostly of trenches, is the deepest area of the oceans. Although representing only $1-2 \%$ of the global ocean benthic area, the hadal zone constitutes $45 \%$ of the ocean depth ${ }^{1}$. Thus, the hadal zone is characterized by high hydrostatic pressure, with other physical and chemical parameters similar to the abyssal oceans ${ }^{2}$. Early studies postulate that the hadal zone is typified by scarce food and low input of organic matter ${ }^{3}$. However, recent studies have shown that the trench sediment had abundant sedimentary organic carbon ${ }^{4}$. Microbiological and biogeochemical investigations showed unexpected high microbial abundance, diversity and activities ${ }^{5}$. Furthermore, a large number of piezotolerant and piezophilic bacteria and archaea, such as Photobacterium, Shewanella, Thermococcus, and Pyrococcus ${ }^{6}$, have been isolated from trench sediment and other matrices ${ }^{7}$. The mechanisms of microbial adaptation to high hydrostatic pressure (HHP) have been elucidated, such as biosynthesis of unsaturated membrane lipids, transporters, and motility and respiratory chain components ${ }^{8,9}$.

Deep-sea microorganisms are important members of halobios, which can produce novel substances with antibacterial, anti-tumor, anti-protease, and anti-virus activities ${ }^{10}$. Among them, fungi are considered as the most promising drug source for sustainable utilization ${ }^{11}$. According to previous studies, $75 \%$ of natural products produced by deep-sea fungi have bioactivity and $40 \%$ of those have the potential to be drug candidates ${ }^{12}$. The first fungus isolated from the Mariana Trench was reported by Takami ${ }^{13}$. Since then, a number of fungi species have been isolated from the deep ocean ${ }^{10,14-19}$. More and more bioactive compounds isolated from deep-sea derived fungi have been published ${ }^{20}$. Up until now, there have been only a few reported piezotolerant fungi isolated from the deep ocean, and no piezophilic fungi from the hadal zone have been reported. Some of the deep-sea fungi can grow at pressures up to $20 \mathrm{MPa}^{21}$ and the growth characteristics were described under the simulated deep-sea conditions ${ }^{15,22}$. It was reported that hydrostatic pressure appeared to play a role in the developments of mycelium and spores, as was typical of the genus Aspergillus ${ }^{22}$. Several fungal isolates showed abnormal phenotypes under elevated pressure, implying that HHP would change the life process of fungi in the deep sea. Although recent studies have reported diverse fungi from the deep ocean, isolation and cultivation of marine fungi under HHP conditions from the hadal sediment have not been reported thus far. Furthermore, most of the reported fungal secondary metabolites are produced under atmospheric conditions. The novel biosynthetic pathway of secondary 


\begin{tabular}{|l|l|l|l|}
\hline Sample & Location & Water depth $(\mathbf{m})$ & Sediment depth $(\mathbf{c m})^{*}$ \\
\hline A & $11.327^{\circ} \mathrm{N}, 142.188^{\circ} \mathrm{E}$ & 10,954 & $0-18$ \\
\hline B & $10.761^{\circ} \mathrm{N}, 142.274^{\circ} \mathrm{E}$ & 5437 & $0-10$ \\
\hline C & $10.761^{\circ} \mathrm{N}, 142.274^{\circ} \mathrm{E}$ & 5437 & $10-20$ \\
\hline D & $10.942^{\circ} \mathrm{N}, 141.768^{\circ} \mathrm{E}$ & 7332 & $0-10$ \\
\hline E & $10.942^{\circ} \mathrm{N}, 141.768^{\circ} \mathrm{E}$ & 7332 & $60-70$ \\
\hline F & $10.813^{\circ} \mathrm{N}, 141.180^{\circ} \mathrm{E}$ & 6477 & $0-10$ \\
\hline G & $10.813^{\circ} \mathrm{N}, 141.180^{\circ} \mathrm{E}$ & 6477 & $30-40$ \\
\hline
\end{tabular}

Table 1. Information for sediment samples used in this study. The samples are named A-G. *Approximate depth, as these samples were from subsampling of box cores.

metabolites under in-situ environmental conditions is not known. That impedes the exploration of deep-sea life processes and limits the utilization of these natural microbial resources.

In this paper, we report the isolation of sediment fungi from the Mariana Trench, and show that the development and production of secondary metabolites of these fungi are influenced by growth pressure. Our study represents the first report of 8 fungi in the Mariana Trench sediment and the special life processes of the hadal fungi under extreme high pressure conditions.

\section{Materials and methods}

Study site and sample collection. Sediment samples were collected from water depths of 5437 to $10,954 \mathrm{~m}$ in the Mariana Trench $\left(11^{\circ} 20^{\prime} \mathrm{N}, 142^{\circ} 11.5^{\prime} \mathrm{E}\right)$ on board of the 15 th expedition of the Discovery-One research vessel (TS 15) in November 2019. A box corer was used to collect four sediment samples at depths of 5437, 6477, 7332 and 10,954 $\mathrm{m}$ in the Mariana Trench (Table 1). To prevent contamination, the sealed box corer was used during the sampling process. Sterilized shovels were used to scrape off the surface sediments $(\mathrm{ca} .5 \mathrm{~cm})$ of the box cores. All the parts of the samples that touched the sampler were discarded. The center part of the sediment core was subsampled and stored in sterile plastic bags immediately at $4{ }^{\circ} \mathrm{C}$ for subsequent experiments. In the laboratory, the sediment samples were scraped with a sterilized spoon and placed in a sterile centrifuge tube for subsequent fungal isolation experiments.

Fungal isolation and identification. The method of isolating and culturing fungi from deep-sea sediments was the same as the method of isolating bacteria ${ }^{16}$. An aliquot of sediment from the central part of the subsection was removed with a sterile spatula and placed in sterile vials for isolation ${ }^{16}$. Unless otherwise specified, Potato Dextrose Agar (PDA, 20\% peeled and sliced potato, 1.0\% glucose, and 1.5-2\% agar, with deep-sea in-situ seawater, natural $\mathrm{pH}$ ) was the routine media for the fungi. About $5 \mathrm{~g}$ of the sediment samples were placed in a $50 \mathrm{ml}$ sterile centrifuge tube. $45 \mathrm{ml}$ of deep-sea in-situ seawater which has been autoclaved were added into the tube, and mixed well. The sample was evenly spread on a PDA plate $(100 \mathrm{ng} / \mathrm{ml}$ gentamicin or $100 \mathrm{ng} / \mathrm{ml}$ ampicillin), and then cultured at $28^{\circ} \mathrm{C}$ for 7 days. The hyphaend-purification skill was used to isolate and purify the fungi. The individual strains were cultured on PDA medium at $28{ }^{\circ} \mathrm{C}$. Hyphal growth and pigment production were observed and photographed every day. The Nikon DS-Ri2 was used to check hyphal growth and spore production. The species identification of fungi was carried out by combining morphological characteristics and internal transcription interval (ITS) sequences analysis.

DNA extraction, PCR amplification, and clone library construction. The fungi were cultured in potato dextrose broth (PDB, 20\% peeled and sliced potato and $1.0 \%$ glucose, with deep-sea in-situ seawater, natural $\mathrm{pH}$ ) for 7-14 days for DNA isolation. Fungal genomic DNA was extracted from all targeted fungal strains using the TIANcombi DNA Lyse \& Det PCR Kit (TIANGEN BIOTECH (BEIJING) CO., LTD). A partial region of $18 \mathrm{~S}$ rDNA (nearly full length ITS sequences) was amplified by polymerase chain reaction with the primers ITS1 (5'-TCCGTAGGTGAACCTGCGG-3') and ITS4 (5'- TCCTCCGCTTATTGATATGC-3' ${ }^{23}$. Polymerase chain reaction mixture $(20 \mu \mathrm{l})$ was composed of $10 \mu \mathrm{l} 2 \times$ Det PCR MasterMix, with $0.5 \mu$ l forward primer and $0.5 \mu \mathrm{l}$ reverse primer, DNA template, and $\mathrm{dd}_{2} \mathrm{O}$. The PCR amplification process was as follows: starting with 3 min of denaturation at $95^{\circ} \mathrm{C}$, followed by 35 cycles of PCR $\left(30 \mathrm{~s}\right.$ at $95^{\circ} \mathrm{C}, 30 \mathrm{~s}$ at $55^{\circ} \mathrm{C}$, and then $1 \mathrm{~min}$ at $\left.72^{\circ} \mathrm{C}\right)$, prolonged at $72^{\circ} \mathrm{C}$ for $5 \mathrm{~min}$. The amplified DNA sequences were analyzed by GENEWIZ for ITS sequencing.

Phylogenetic analyses. The sequencing results were blasted in the NCBI database to determine the taxonomy of the isolates. All of the vector sequences from the sequenced fungal clones were analyzed using the rRNA Database Project CHECK CHI MERA program to detect and eliminate the potential chimeric sequences ${ }^{24}$. Pairwise alignment of the sequences was conducted using Clustal W in the MEGA7 software. Conserved motifs were identified, and the sequences were trimmed manually ${ }^{25}$. More than $98 \%$ of similar species were constructed into evolutionary trees to explore the species of the obtained strains.

High-pressure cultivation and morphological observation. To observe if the fungal spores still have germination activity after the treatment of preset pressure, high-pressure tolerant assay was performed. The 


\begin{tabular}{|l|l|l|l|l|l|l|l|l|}
\hline Sample & CIEL 1 & CIEL 2 & CIEL 3 & CIEL 4 & CIEL 5 & CIEL 6 & CIEL 7 & CIEL 8 \\
\hline$/ \mathrm{ml}$ & 15 & $4.5 \times 10^{5}$ & $6.5 \times 10^{5}$ & $1.0 \times 10^{5}$ & 70 & 20 & $1.0 \times 10^{5}$ & $2.5 \times 10^{5}$ \\
\hline
\end{tabular}

Table 2. The initial inoculation amounts of each strain for high-pressure cultivation.

above-isolated strains were inoculated in the PDB at $28^{\circ} \mathrm{C}$ for 10 days. Then fungal cultures were filtered with 8 -layer sterile gauze to separate the hyphae and spores. The numbers of spores inoculated for each sample were shown in Table 2. A syringe was used to pick up $1 \mathrm{ml}$ of spore filtrate of each strain as the targeted samples. The prepared samples were incubated for one week at a preset pressure, $0.1,20$, or $40 \mathrm{MPa}$. Once finished, $100 \mu \mathrm{l} \mathrm{cul-}$ ture medium was re-inoculated on PDA medium supplemented with $100 \mu \mathrm{g} / \mathrm{ml}$ ampicillin (AMP) and then cultured at $28{ }^{\circ} \mathrm{C}$ under atmospheric pressure. Hyphal growth and colony morphology of the fungi were observed and recorded every day. This procedure was repeated for all the sediment samples.

For microscopy observation, $20 \mu \mathrm{l}$ of culture was dropped in the center of the glass slide, mixed with $20 \mu \mathrm{l}$ of Calcium Fluorescent white stain (Sigma-Aldrich) in the dark for $1 \mathrm{~min}$. The microscopic morphology of the hyphae and spores of individual strains were observed under a fluorescence microscope (Nikon DS-Ri2) with a magnification of $\times 100$ to $\times 400$ times of ultraviolet light.

Secondary metabolites. To determine the secondary metabolites produced by hadal fungi under different pressures, the fermentation and extraction of the fungi were performed. The fungal inoculation process, growth, culture conditions, and extraction of secondary metabolites were performed using the method as described in a previous study with minor modifications ${ }^{26}$. The 8 individual fungi were cultured under the three different pressures for one week. Then the same amounts of spores of each targeted strain were inoculated into $200 \mathrm{ml}$ PDB medium, shaken at $180 \mathrm{rpm}, 28^{\circ} \mathrm{C}$, for 14 days. The mycelium and liquid were separated by vacuum filtration with 8 layers of sterilized gauze, then the two parts were extracted twice with an equal volume of ethyl acetate overnight ${ }^{27}$. The organic fractions were collected and combined. The solvent was then removed by vacuum rotary evaporator at $45^{\circ} \mathrm{C}$. The obtained crude extract was dissolved in $1 \mathrm{ml}$ methanol for subsequent analysis.

UPLC-MS analysis. LC-Mass spectrometric analyses were performed using a Vanquish UPLC high-resolution mass spectrometer (Thermo Fisher) equipped with an electrospray ionization (ESI) source operating in the positive ion and negative mode. A Waters ACQUITY UPLC BEH C18 column $(1.7 \mu \mathrm{m} \times 2.1 \mathrm{~mm} \times 100 \mathrm{~mm})$, at a flow rate of $0.4 \mathrm{ml} / \mathrm{min}$, was used for preparative HPLC collection. The column temperature was held at $60{ }^{\circ} \mathrm{C}$, and the injection temperature was held at $10^{\circ} \mathrm{C}$. The culture extracts were dissolved in $1 \mathrm{ml}$ solvent (methanol: acetonitrile, 2:1, v/v) using a sonication bath for $5 \mathrm{~min}$. Samples were centrifuged for $15 \mathrm{~min}$ and $400 \mu \mathrm{l}$ of the supernatants were used for UPLC-MS analysis.

Antimicrobial activity assay. The indicator bacteria used in the bacteriostatic circle experiment were provided by Shanghai Rainbowfish Company, including Staphylococcus aureus ATCC25923, Enterococcus faecalis FA2-2, Escherichia coli MG1655, Chromobacterium violaceum ATCC12472 CV026, Candida Albicans desertification, mycobacterium smegmatis, Pseudomonas aeruginosa PA01, Pseudomonas aeruginosa 484, Pseudomonas aeruginosa 554, Pseudomonas aeruginosa C218.

Antibacterial activity of the fungal extracts was performed using the standard disc diffusion method. The indicator bacteria culture solution (OD of approximately 0.5 ) was evenly spread on LB (Luria-Bertani, $5 \mathrm{~g}$ yeast extract, $10 \mathrm{~g}$ tryptone, $10 \mathrm{~g}$ sodium chloride, adjust the $\mathrm{pH}$ to 7.0), at an inoculum of $50 \mu \mathrm{l}$. The sterilized round filter paper sheets were attached to the LB. Then $6 \mu$ of the crude extracted metabolites was dropped on the round filter paper sheet. Antibacterial assay was evaluated by measuring the diameters of inhibition zones, after incubated at $37^{\circ} \mathrm{C}$ for $16 \mathrm{~h}$. Empty solvent (ethyl acetate) was taken as a control for antibacterial activities. The areas of inhibition zones were measured using Image J, and repeated three times.

\section{Results}

Phylogeny of environmental fungal ITS-rDNA sequences. A total of 42 individual fungal strains were isolated from the Mariana Trench sediments in this study. High-pressure incubation and germination recovery of cultivable fungi were performed as described above. Through pressure screening, 8 sporulating filamentous fungi were selected as the targeted fungi for further analysis.

The phylogenetic tree was constructed by the MEGA7 software based on the ITS sequence (ITS1/ITS4 primer set) (Fig. 1). These 8 individual fungi belong to 6 different species, Stemphylium sp., Cladosporium sp., Arthrinium sp., Fusarium sp., Alternaria sp., and Aspergillus sp. Although the blast sequences were $100 \%$ similar to those of known fungal strains in the database, only two of the 8 individual fungal were determined at species level while the other 6 were identified only at genus level. Moreover, the sequences of some individual fungi showed $100 \%$ similarity to two or more species in the database alignments. Therefore, identification was also carried out by the typical morphological taxonomy, combined with molecular identification. Based on these characterizations, the 8 fungi were named as Alternaria alternata CIEL 1, Cladosporium sp. CIEL 2, Aspergillus sp. CIEL 3, Arthrinium sp. CIEL 4, Stemphylium vesicarium CIEL 5, Alternaria sp. CIEL 6, Fusarium poae CIEL 7, and Cladosporium sp. CIEL 8 (Table 3). These results suggested the presence of cultivable fungal populations in the Mariana Trench sediments. 


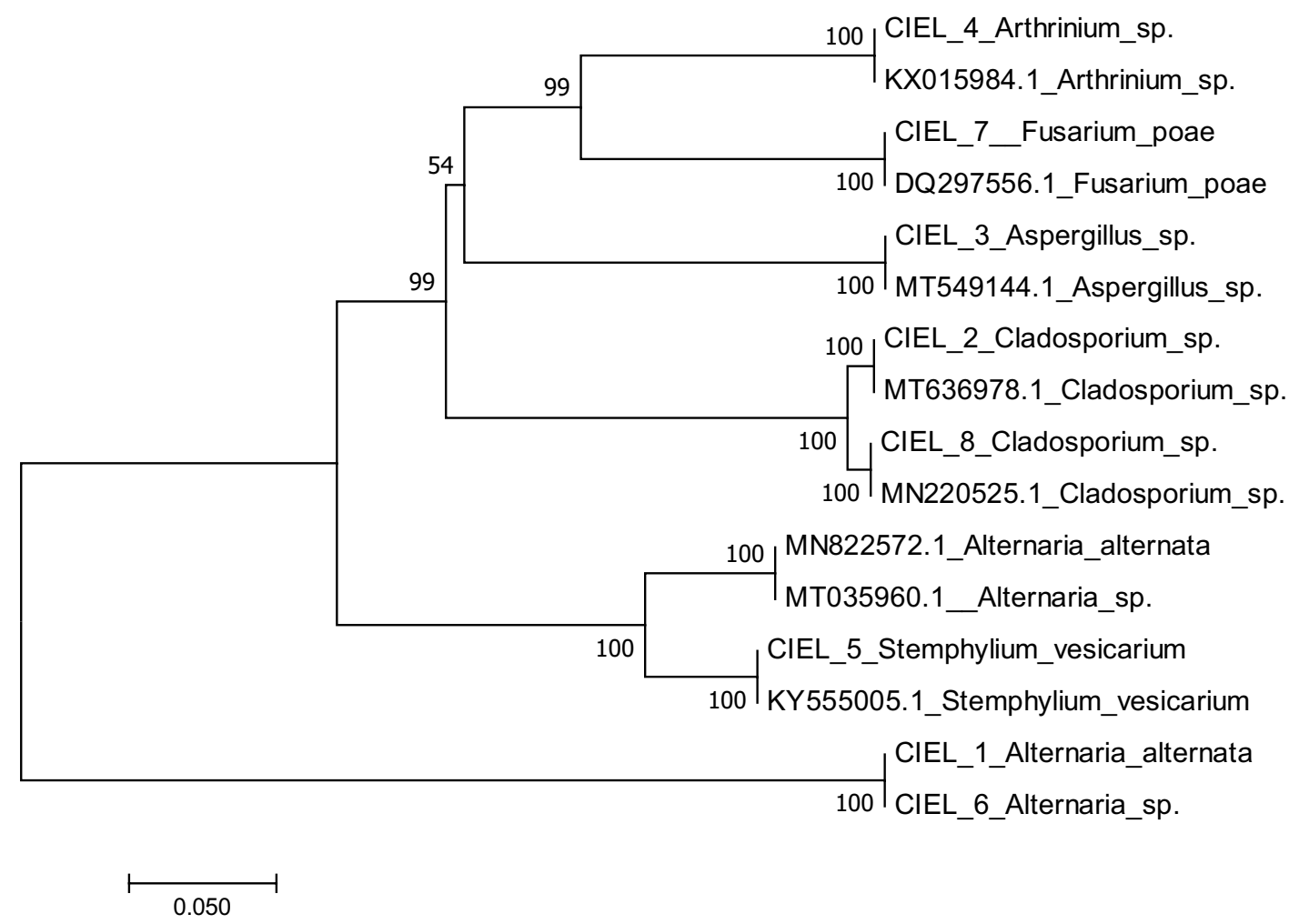

Figure 1. Phylogenetic tree of ITS sequences (ITS1/ITS4 primers) of the eight fungi isolated from deep-sea sediments in the Mariana Trench.

\begin{tabular}{|c|c|c|c|c|}
\hline No & Name & GenBank accession no & Fungal genera or species & Sample (sediments) \\
\hline CIEL 1 & Alternaria alternata CIEL 1 & MN822572.1 & Alternaria alternata & B \\
\hline CIEL 2 & Cladosporium sp. CIEL 2 & MT636978.1 & Cladosporium sp. & $\mathrm{D}$ \\
\hline CIEL 3 & Aspergillus sp. CIEL 3 & MT549144.1 & Aspergillus sp. & $\mathrm{C}$ \\
\hline CIEL 4 & Arthrinium sp. CIEL 4 & KX015984.1 & Arthrinium sp. & $\mathrm{F}$ \\
\hline CIEL 5 & Stemphylium vesicarium CIEL 5 & KY555005.1 & Stemphylium vesicarium & $\mathrm{D}$ \\
\hline CIEL 6 & $\begin{array}{l}\text { Alternaria sp. } \\
\text { CIEL } 6\end{array}$ & MT035960.1 & Alternaria sp. & G \\
\hline CIEL 7 & Fusarium poae CIEL 7 & DQ297556.1 & Fusarium poae & $\mathrm{C}$ \\
\hline CIEL 8 & Cladosporium sp. CIEL 8 & MN220525.1 & Cladosporium sp. & $\mathrm{C}$ \\
\hline
\end{tabular}

Table 3. Species information for hadal-derived fungi isolated and cultured in this experiment.

Fungal characterization and identification. To characterize the isolated strains, morphological identifications of the 8 fungal colonies were performed, including microscopy observations. All the hyphae were permeable to the Calcofluor white (CFW) stain. A. alternata CIEL 1 was a filamentous fungus that produced a gray-white thick colony and finally turned dark brown to black. Under the microscope, the dark-brown spores appeared larger with fine longer septa. After 14 days on PDA at $28{ }^{\circ} \mathrm{C}$, the colony reached $6 \mathrm{~cm}$ diameter. Another species, Alternaria sp. CIEL 6, showed the typical characteristics of Alternaria sp., with distinctive septate and club-shaped spores. After 14 days on PDA at $28{ }^{\circ} \mathrm{C}$, the colony reached 6-cm diameter, and created the dark green pigment. The basal hyphae were pigmented under the microscopic view (Figs. 2, S1).

Cladosporium sp. CIEL 2 and Cladosporium sp. CIEL 8 belong to the same species. The two species developed brown colonies with smooth edges and wrinkled surface. Under the microscope, both species produced dark-pigmented spores and branched hyphae. The fascicled spores were ovoid, round, or irregularly shape. Cladosporium sp. CIEL 2 colony diameter reached 3-4 cm after 7 days on PDA at $28{ }^{\circ} \mathrm{C}$. But the diameter of Cladosporium sp. CIEL 8 colony reached $4-5 \mathrm{~cm}$ after 7 days on the same medium and temperature (Figs. 2, S1).

Aspergillus sp. CIEL 3 belongs to a common species widely distributed in different environments. It produced distinctive uniseriate and columnar conical heads with the phialides, under the microscope. After 7 days on PDA at $28^{\circ} \mathrm{C}$, the colony reached $4-5 \mathrm{~cm}$ diameter. The color of the colony was blue. The hyphae and scattered spherical conidiophores were colorless (Figs. 2, S1). 


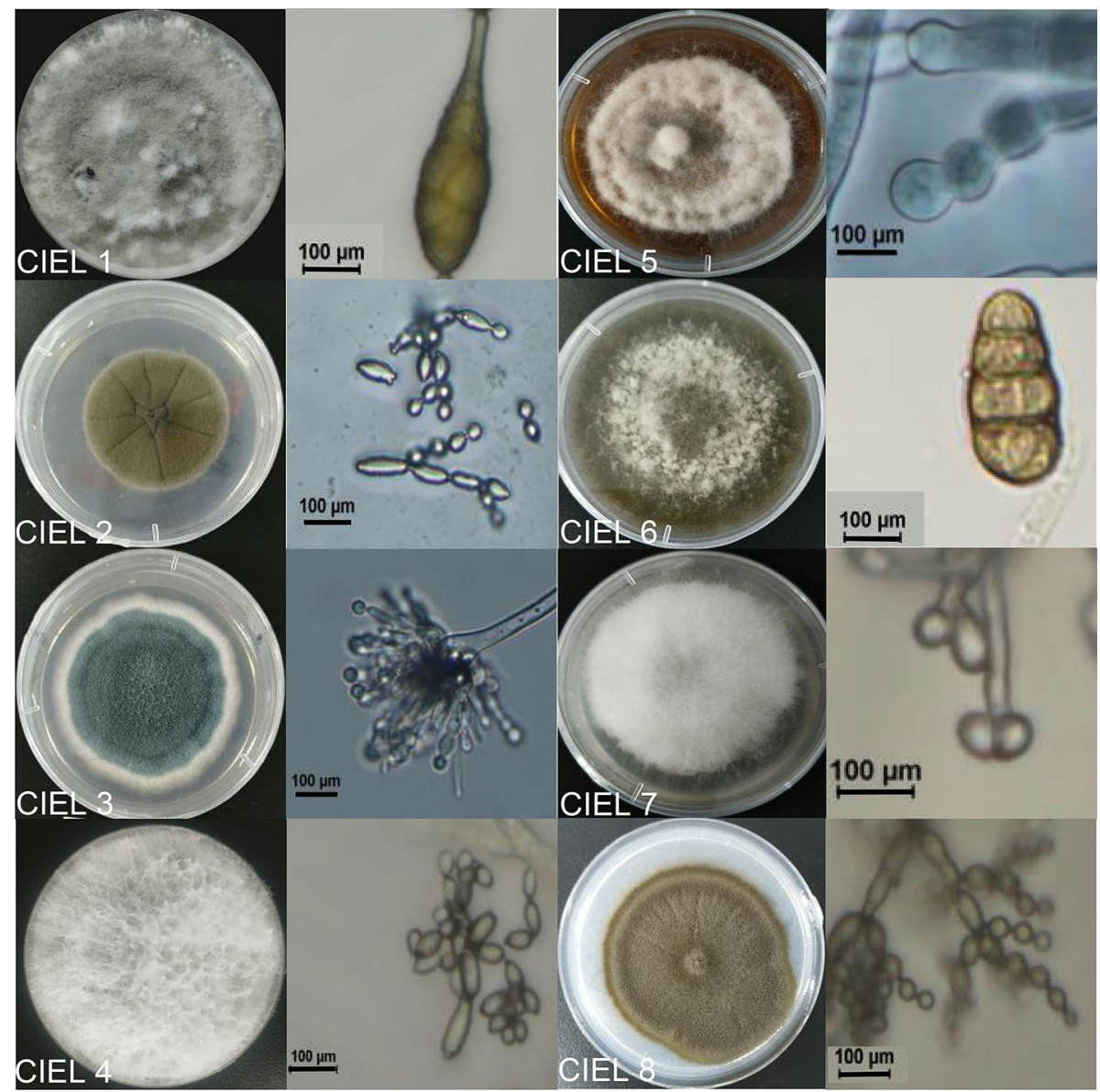

Figure 2. The typical spore patterns of 8 strains were obtained in the Mariana Trench sediment under atmospheric pressure. Macroscopic images showed the morphology of colony. Microscopic images showed the morphology of typical spores, taken under $\times 40$ microscopes. The scale bar was $100 \mu \mathrm{m}$.

F. poae CIEL 7 was also isolated from sediment C, which belongs to a large genus of filamentous fungi. Here, after 7 days on PDA at $28^{\circ} \mathrm{C}$, the colony reached $4-5 \mathrm{~cm}$ diameter. It developed oval or spindle-shaped spores and colorless hyphae, extending in the branched mycelium. Conidiophores were short and loosely branched (Figs. 2, S1).

Arthrinium sp. CIEL4 grew fast and developed into a white, floccose, spreading colony, brown to black spore clusters with time. After 7 days on PDA at $28{ }^{\circ} \mathrm{C}$, the colony reached $6 \mathrm{~cm}$ in diameter. It produced small lemonor olive-shaped spores with characteristic features, under the microscope (Figs. 2, S1).

S. vesicarium CIEL 5 matched $100 \%$ similarity to S. vesicarium. After 7 Days on PDA at $28{ }^{\circ} \mathrm{C}$, the colony reached $4-5 \mathrm{~cm}$ in diameter, and then there was no significant change in the colony diameter. S. vesicarium CIEL 5 developed a white colony and turned brown to tan in the center, secreting orange pigment into the medium. Spores were dark in color, few branching. Conidia were porous, monoculture at the distended end of the pedicel or spores were produced continuously at the tip (Figs. 2, S1).

Hydrostatic pressure impacts the germination and vegetative growth of hadal sediment fungi. Among the 8 isolated hadal fungi, all except $S$. vesicarium CIEL 5 possessed the ability of germination after being incubated under the pressure of $40 \mathrm{MPa}$. The percentage of spores germination under different pressures was $20-50 \%$. CIEL 5 did not germinate after 7 days' high-pressure incubation and no mycelium was developed after another 7 days' atmospheric-pressure cultivation (Fig. 3). The spore phenotypes of 8 hadal-sedimentderived fungi, cultured under different hydrostatic pressures were observed in this study. There was no obvious change of spores structure before and after HPP treatment (Fig. S2). Those results suggested that high-pressure impacts germination of these fungal species (CIEL 5), but no obvious effect on the phenotype of fungal spores.

Next, we performed phenotype characterization and measured colony areas of the fungal strains cultured under different pressures. Among the eight individual fungi, some of the fungal colonies developed significantly larger areas on the plates under atmospheric pressure than under high pressures, such as CIEL 1, CIEL 5, CIEL 6, and CIEL 8, while other fungi grew better under high pressure, such as CIEL 2, CIEL 3, CIEL 4, and CIEL 7 (Fig. 4). Coloration of these fungi was also influenced by hydrostatic pressure. The fungal colonies of CIEL 3 and CIEL 7 developed distinct phenotypes under different pressures. Colonies of CIEL 3 were dark-green under 
a
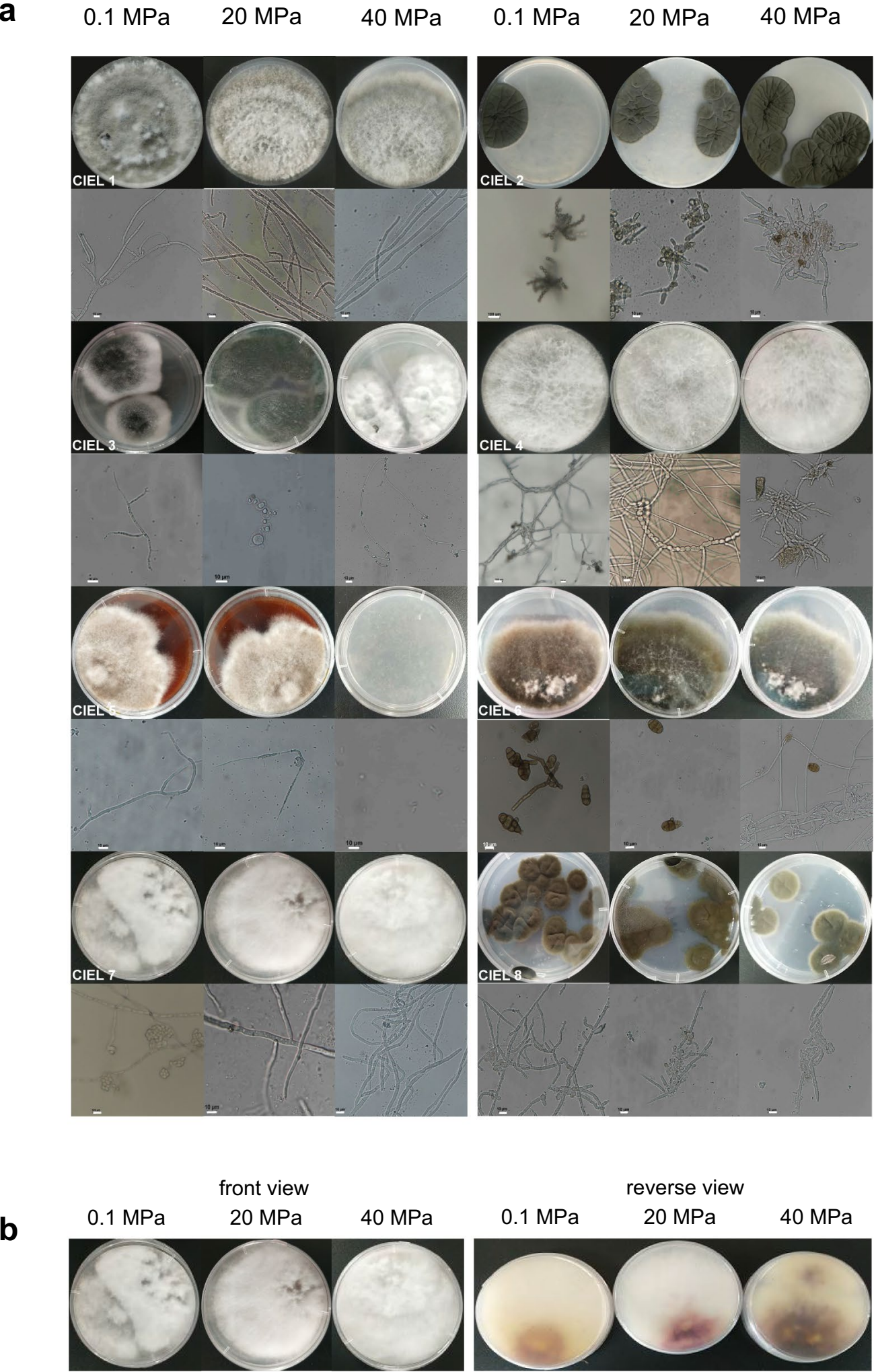

Figure 3. Phenotypes of hadal-derived fungi isolated and cultured in this experiment under the different preset pressures. (a) Colony, mycelium and spore morphology of eight fungi were obtained, respectively, under $0.1,20$ and 40 MPa. (CIEL 1) Alternaria alternata CIEL1, (CIEL 2) Cladosporium sp. CIEL 2, (CIEL 3) Aspergillus sp. CIEL 3, (CIEL 4) Arthrinium sp. CIEL 4, (CIEL 5) Stemphylium vesicarium CIEL 5, (CIEL 6) Alternaria sp. CIEL 6, (CIEL 7) Fusarium. poae CIEL 7, (CIEL 8) Cladosporium sp. CIEL 8. (b) Growth state of Fusarium poae CIEL 7 under $0.1,20$ and $40 \mathrm{MPa}$. There was no significant difference in the front side of the colonies, but the back side of the colonies showed different colors. 


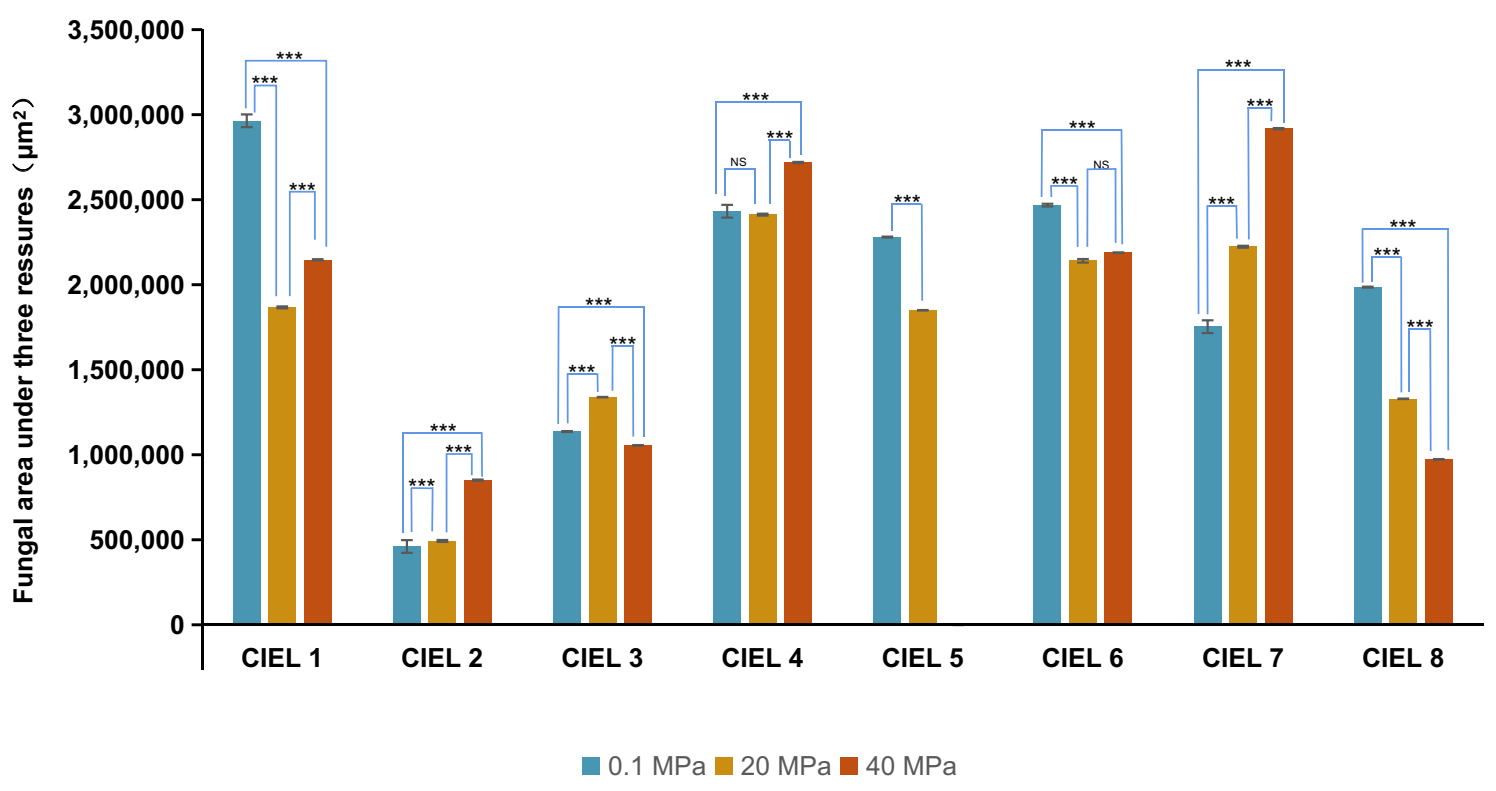

Figure 4. The growth rate of hadal-derived fungi isolated and cultured in this experiment under the different preset pressures. Under the same cultural conditions, the area of the strain changed regularly with the change of pressure. The unit of the area was $\mu \mathrm{m}^{2}$. T-test was used for pairwise comparisons. (NS $p>0.05,{ }^{* *} p<0.001$ ).

atmospheric pressure, and green under $20 \mathrm{MPa}$. The pigment produced by CIEL 7 was yellowish under normal pressure, purple-red under $20 \mathrm{MPa}$, and blackish under $40 \mathrm{MPa}$ (Fig. 3). Based on these results, we conclude that high hydrostatic pressure influences germination, vegetative growth, and pigmentation of the Mariana Trench sediment- derived fungi.

High hydrostatic pressure influences the production of secondary metabolites. In this study, the secondary metabolites of the 8 individual fungi were extracted and characterized. To better understand the impact of hydrostatic pressure on the production of secondary metabolites, the UPLC-MS experiment was performed. In the comparison of metabolites from the same strain under different hydrostatic pressures, different mass peaks in the total ion chromatogram (TIC) were observed (Fig. 5). For CIEL 2, the amounts of compound $1,2 / 4,3$ with retention times (RT) at $3.49,3.65,4.32 \mathrm{~min}$, were changed respectively because of the treatment pressure. Through blasting in the NIST chemical database, the compounds were identified as $\mathrm{C}_{21} \mathrm{H}_{29} \mathrm{ON}_{3}$, $\mathrm{C}_{17} \mathrm{H}_{29} \mathrm{O}_{3} \mathrm{~N}_{7} / \mathrm{C}_{16} \mathrm{H}_{27} \mathrm{ON}_{7}$, and $\mathrm{C}_{27} \mathrm{H}_{41} \mathrm{ON}_{3}$, respectively. In addition, as shown in Fig. $\mathrm{S} 3$, compounds 2 and 4 had the same retention time, but not one compound. The new peak 5 (RT at $6.6 \mathrm{~min}$ ) was observed in the TIC of CIEL 5 after high pressure treatment at $20 \mathrm{MPa}$. The putative compound was identified as $\mathrm{C}_{16} \mathrm{H}_{45} \mathrm{O}_{8} \mathrm{~N}_{9}$. Further characterization is needed to determine the exact chemical structure of these compounds. Our results indicated that fungal growth pressure probably affected expression of genes associated with biosynthesis of these compounds. Further, the production of secondary metabolites changed with fungal growth pressure. This hypothesis was further tested by antimicrobial assay.

The antibacterial bioactivity of secondary metabolites and the influences of hydrostatic pressure. To determine the bioactivity of these natural products, antimicrobial assay was performed against 10 pathogenic bacteria via the Kirby-Bauer test. Among the 8 fungal strains, Cladosporium sp. CIEL 2, S. vesicarium CIEL 5, and Cladosporium sp. CIEL 8 displayed antibacterial activity against S. aureus ATCC25923 and E. faecalis FA2-2. The diameters of the inhibition zones were measured as shown in Fig. 6. First, the extract of Cladosporium sp. CIEL 2 cultured under atmospheric pressure showed no antibacterial activity. However, the extracts from the same strain (CIEL 2) incubated under $20 \mathrm{MPa}$ and $40 \mathrm{MPa}$ exhibited remarkably high inhibition effects on S. aureus ATCC25923 and E. faecalis FA2-2. Second, S. vesicarium CIEL 5, cultured under $0.1 \mathrm{MPa}$ and $20 \mathrm{MPa}$, produced brownish pigments in the crude extract, and lost the ability of germination at $40 \mathrm{MPa}$. Compared with other fungal metabolites, the extracts of CIEL 5 cultured under $0.1 \mathrm{MPa}$ and $20 \mathrm{MPa}$ had the most significant antibacterial effects on S. aureus ATCC25923 and E. faecalis FA2-2. Third, secondary metabolites produced by Cladosporium sp. CIEL 8 under the three pressures all showed inhibition activities against both S. aureus ATCC25923 and E. faecalis FA2-2. The size of the inhibition zones appeared smaller gradually as growth pressure increased (Fig. 6). Our results showed the vast potential of the hadal fungi to be exploited as the producer of bioactive compounds. Furthermore, it was assumed that the genes associated with biosynthesis of secondary metabolites could be activated by the high-pressure treatment, implying the HHP influenced the production of natural products and life process of the Mariana Trench-derived fungi. 

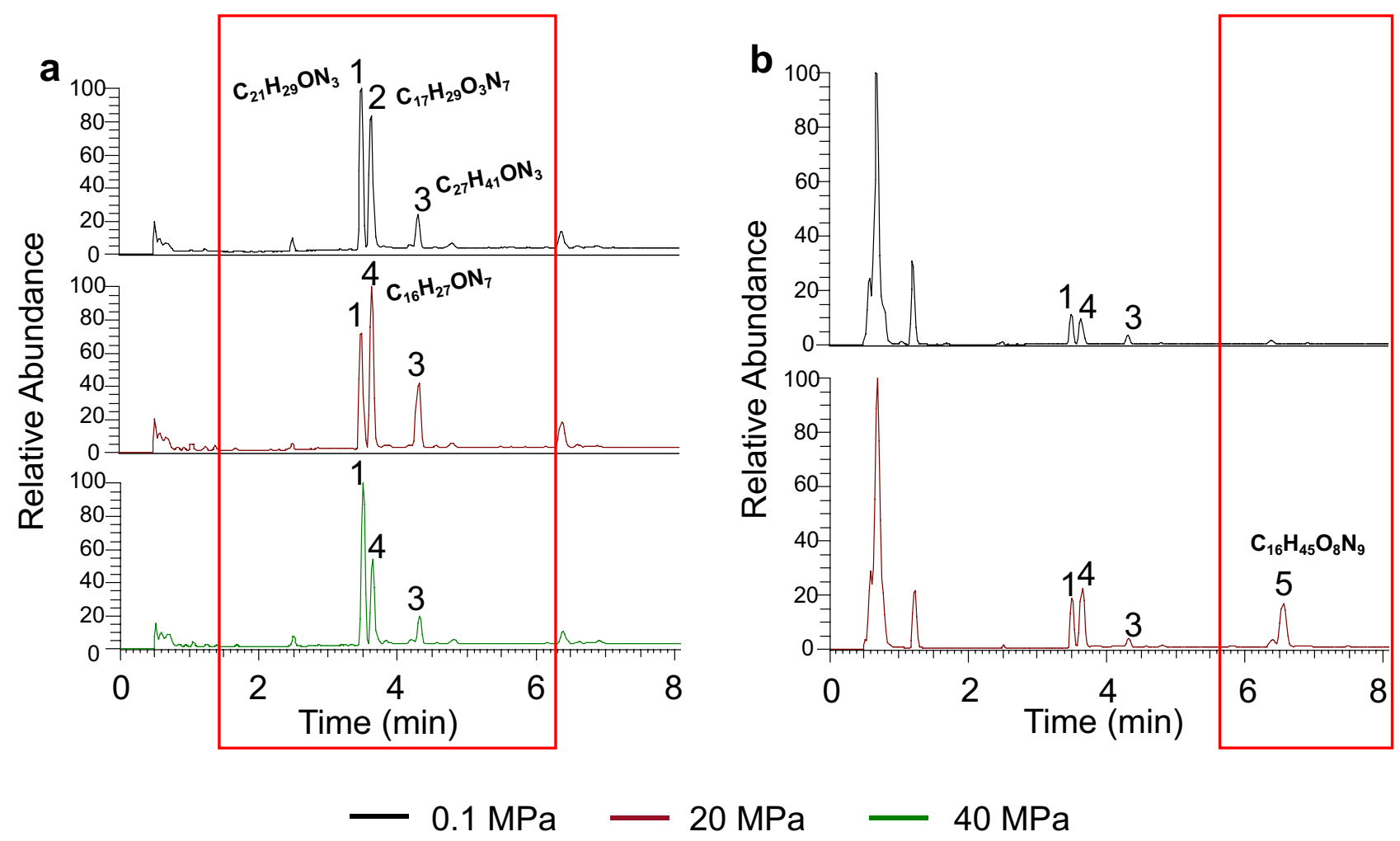

Figure 5. TIC diagrams of metabolites of hadal-derived fungi isolated and cultured under three preset hydrostatic pressures. (a) TIC peak of Cladosporium sp. CIEL 2 at different hydrostatic pressures. In addition to the change of peak intensity, 4 but not 2 appeared in the metabolites at $20 \mathrm{MPa}$ and $40 \mathrm{MPa}$. (b) TIC peak of Stemphylium vesicarium CIEL 5 at different hydrostatic pressures. A new peak 5 appears at $20 \mathrm{MPa}$. Each analysis shows the extracted ion track of the corresponding compounds recorded by mass spectrometry. The relative abundance was set at 100 .

\section{Discussion}

In our report, six species of Alternaria sp., Cladosporium sp., Aspergillus sp., Arthrinium sp., Stemphylium sp., and Fusarium sp. isolated from the Mariana Trench sediments are reported for the first time. Prior to this report, sediment fungal communities were mostly estimated by metagenomic analysis (culture-independent method), showing the distinct diversity of microorganisms and genetic potential ${ }^{17,28,29}$. Here, our report of isolation of over 40 individual fungal strains will facilitate the development of new biological sources of natural products. Furthermore, the Mariana Trench sediment-derived fungi offer excellent model organisms to study the physiology of HHP-adapted fungi and understand their ecological roles in such extreme environments.

Using classical ITS and morphology-based identification, most of the isolated fungal species were similar to terrestrial fungal species and those derived from the shallow sea. Furthermore, most of the fungi isolated in our study exhibited phylogenetic similarity to the pathogen fungi in the environment. For example, S. vesicarium has wide host range as a plant pathogen, including asparagus, garlic, and pear. Many species of Cladosporium are commonly found on living and dead plant material. Some of them are plant pathogens, others can parasitize other fungi. Arthrinium phyllostachium sp. was isolated from the decaying culms of Phyllostachys heteroclada ${ }^{30}$. Fusarium poae can cause brown necrosis of petals and, sometimes, the death of opening buds. Alternaria alternata is ubiquitous worldwide and can cause black spots in many fruits and vegetables around the world. Aspergillus sydowii is known to cause infection/death in the coral community, also a causative agent for aspergillosis, onychomycosis, and keratomycosis. From these results, we posit that the hadal sediment fungi were probably derived from spores or appressorium of terrestrial fungal strains, which were transported with their host (plants), in the prior time. Then the fungal species from the terrestrial environment have gradually adapted to the extreme trench environment. Further work is needed to verify the origin of the hadal fungi.

Although the adaptation mechanism of piezophilic bacteria in deep-sea environments was well recognized in many reports, the investigations on the adaption of sediment fungi to high hydrostatic pressure of hadal trenches have received very little attention. In our study, most of the isolated fungi germinated and grew normally after the incubation under elevated hydrostatic pressure for 7 days. Only $S$. vesicarium CIEL 5 lost the ability of germination after the treatment of high hydrostatic pressure $(40 \mathrm{MPa})$. Damare and Raghukumar ${ }^{18}$ showed the abnormal phenotype and different biomass of deep-sea fungi under high pressure (30 MPa), compared with that at atmospheric pressure. They reported all deep-sea fungi grow better at $20 \mathrm{MPa}$ and $5{ }^{\circ} \mathrm{C}$ than that cultured at atmospheric pressure in their study ${ }^{18}$. In this study, the Mariana Trench sediment fungi showed different growth rates at $0.1,20$, and $40 \mathrm{MPa}$. Some cultures showed better growth at higher pressure while others preferred atmospheric pressure for growth. We also showed different phenotypes and coloration under different pressures. It 
a

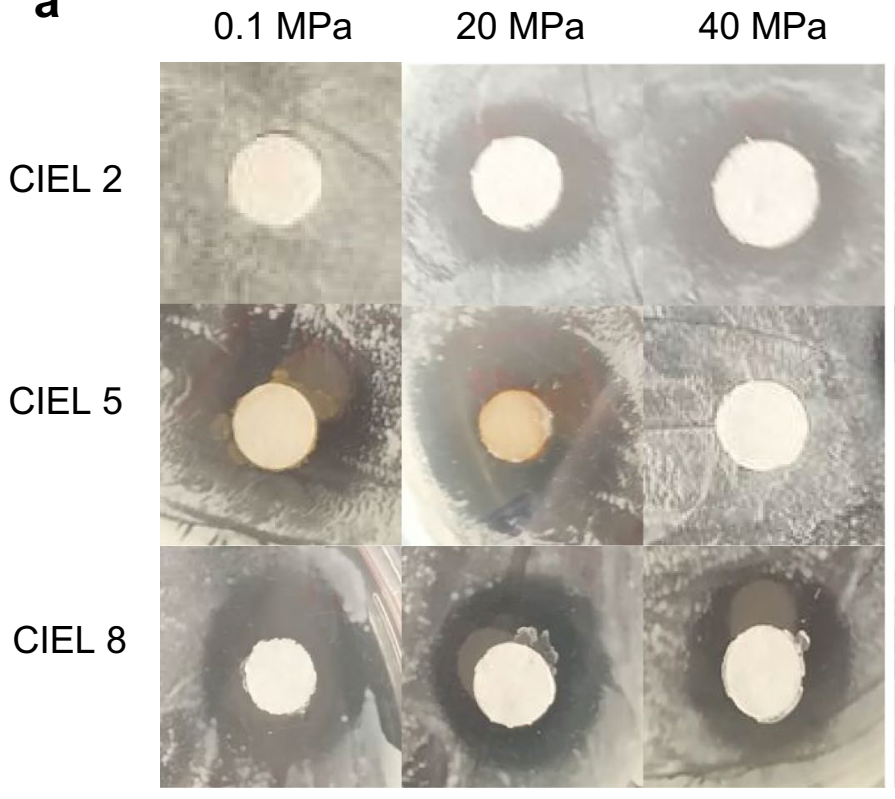

Enterococcus faecalis FA2-2

$0.1 \mathrm{MPa} \quad 20 \mathrm{MPa} \quad 40 \mathrm{MPa}$

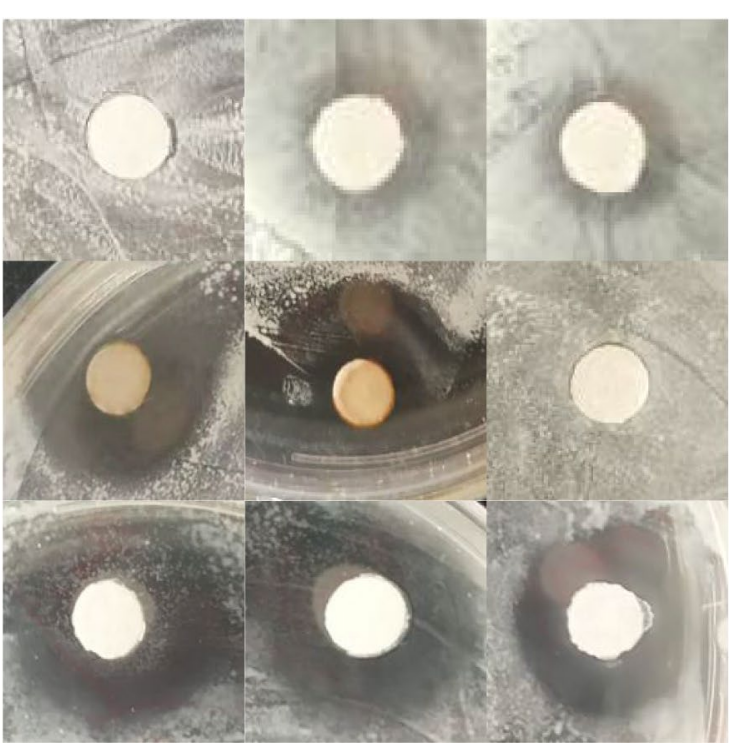

b

\section{Staphylococcus aureus ATCC25923}

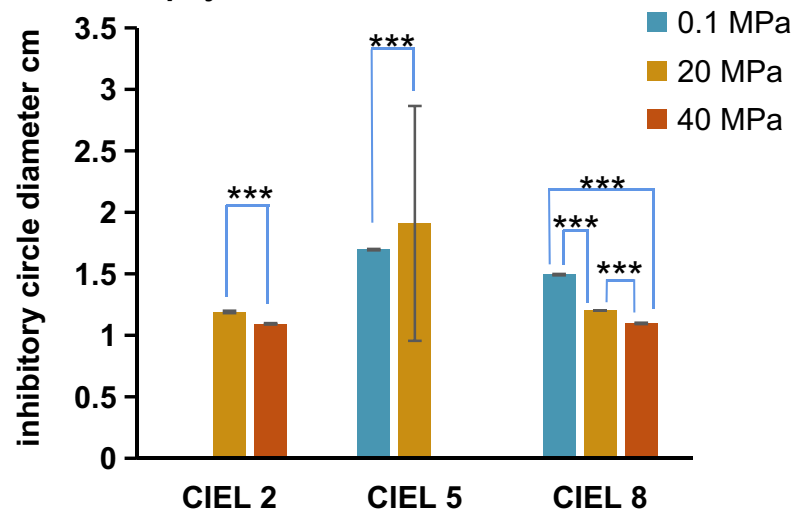

Enterococcus faecalis FA2-2

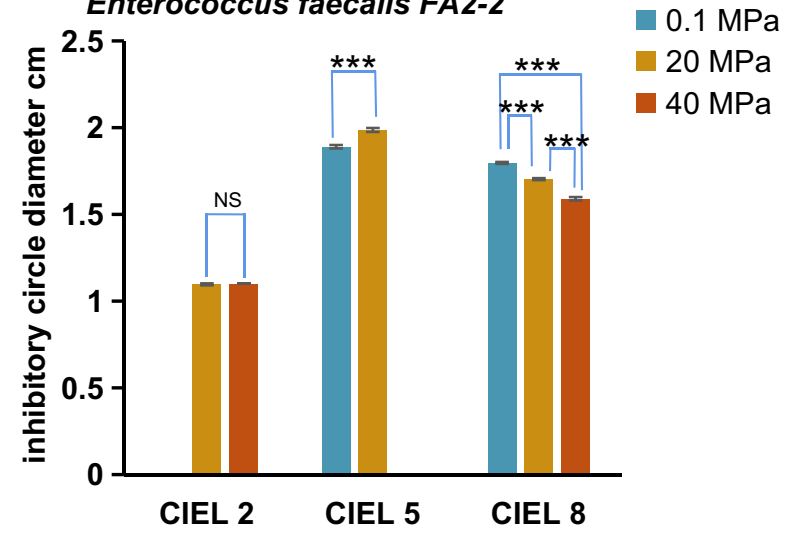

Figure 6. Antimicrobial activity of metabolites of hadal-derived fungi isolated and cultured under three preset hydrostatic pressures. Among the eight strains of fungi isolated in this experiment, Antimicrobial activity of metabolites produced by Cladosporium sp. CIEL 2, Stemphylium vesicarium CIEL 5 and Cladosporium sp. CIEL 8 against Staphylococcus aureus ATCC25923 and Enterococcus faecalis FA2-2 under 0.1, 20 and $40 \mathrm{MPa}$. (a) The inhibitory zone of metabolites produced by fungi under different pressures. (b) Antimicrobial zone diameter of the metabolites against $S$. aureus ATCC25923. The diameter unit was $\mathrm{cm}$. T-test was used for pairwise comparisons. The activity of the Stemphylium vesicarium CIEL 5 metabolic products increases with the increase of pressure. However, the activity of the Cladosporium sp. CIEL 2 and Cladosporium sp. CIEL 8 metabolic products decreases with the increase of pressure. $\left({ }^{* *} p<0.001\right)$. (c) Antimicrobial zone diameter of the metabolites against $E$. faecalis FA2-2. The diameter unit was $\mathrm{cm}$. T-test was used for pairwise comparisons. Cladosporium sp. CIEL 2 metabolic products are inactive, the activity of the Stemphylium vesicarium CIEL 5 metabolic products increases with the increase of pressure, and the activity of the Cladosporium sp. CIEL 8 metabolic products decreases with the increase of pressure (NS $p>0.05,{ }^{* * *} p<0.001$ ).

seems that the fungi evolved into distinct phenotypes, in order to adapt to the extreme environment. The fungal vegetative growth was affected by high hydrostatic pressure, demonstrating that the extreme environmental condition shapes the development of hadal fungi.

Many bioactive natural compounds from deep-sea fungi have been reported. The extreme and distinct growing environments breed the particular secondary metabolisms, biosynthesizing novel natural products ${ }^{19,31,32}$. The deepest sediment harbors the most interesting natural compounds. But most researchers analyze the natural products of deep-sea fungi under laboratory conditions, losing the distinctiveness. Here we reported that the 
productions of secondary metabolites of the fungi were influenced by the pressure condition. Half of the 8 hadal sediment-derived fungi produced antibacterial compounds. The amounts of the bioactive compounds were influenced by growth pressures, indicating that growth pressure plays a role in biosynthesis of secondary metabolites. The distinct pigment production of cultures under different pressures also corroborated the adaptive hypothesis. To our knowledge, the treasure trove of hadal fungi is almost unknown, not to mention the secondary metabolites produced in situ high-pressure cultivation. Only a few studies have reported the natural products of hadal fungi in the lab condition (at atmospheric pressure), lacking in the investigation of ecological adaptation and production of novel secondary metabolites ${ }^{12}$. Our results contribute to paving the way for more exploration and in-depth investigation of specific secondary metabolism in the extreme environment and the relationship between the production of natural products and the environment.

In conclusion, there are few studies on the adaptation mechanisms of deep-sea fungi, especially those living in hadal trenches, and the cognitive exploration of their life processes and genetic resources are extremely limited ${ }^{33,34}$. Therefore, our study of the fungi derived from the Mariana Trench sediments not only contributes to the exploitation of unknown microbial resources in the deep sea, but also has important theoretical significance for the exploration of deep-sea life processes and evolutionary mechanisms, providing a basis for human exploitation and utilization of the biological resources in the Mariana Trench.

\section{Data availability}

All data generated or analysed during this study are included in this published article (and its Supplementary Information files).The datasets supporting the conclusions of this article are available in the NCBI database, GenBank accession numbers list as follows: MZ156971 (CIEL-1), MZ156972 (CIEL-2), MZ156974 (CIEL-3), MZ156973 (CIEL-4), MZ156978 (CIEL-5), MZ156979 (CIEL-6) MZ156981 (CIEL-7), MZ156980 (CIEL-8).

Received: 7 March 2021; Accepted: 19 May 2021

Published online: 01 June 2021

\section{References}

1. Jamieson, A. J. et al. Liparid and macrourid fishes of the hadal zone: in situ observations of activity and feeding behaviour. Proc. Biol. Sci. 276, 1037-1045. https://doi.org/10.1098/rspb.2008.1670 (2009).

2. Nunoura, T. et al. Physiological and genomic features of a novel sulfur-oxidizing gammaproteo bacterium belonging to a previously uncultivated symbiotic Lineage isolated from a hydrothermal vent. PLoS ONE 9, e104959. https://doi.org/10.1371/journal. pone.0104959 (2014).

3. Horikoshi, M., Fujita, T. \& Ohta, S. Benthic associations in bathyal and hadal depths off the Pacific coast of north eastern Japan: physiognomies and site factors. Prog. Oceanogr. 24, 331-339. https://doi.org/10.1016/0079-6611(90)90042-Z (1990).

4. Xu, Y., Ge, H. \& Fang, J. Biogeochemistry of hadal trenches: Recent developments and future perspectives. Deep-Sea Res. Pt. II 155, 19-26. https://doi.org/10.1016/j.dsr2.2018.10.006 (2018).

5. Jebbar, M. Deep sea, the last great unexplored earth frontier harboring the largest unknown and untapped remote microbial diversity on our planet. Res. Microbial. 166, 665-667. https://doi.org/10.1016/j.resmic.2015.08.003 (2015).

6. Fang, J., \& Kato, C. Deep-sea piezophilic bacteria: geomicrobiology and biotechnology. In Geomicrobiology: Biodiversity and Biotechnology (ed. Jain, S. K.) 47-77 (Blackwell, 2010).

7. Kato, C. et al. Extremely barophilic bacteria isolated from the Mariana Trench, Challenger Deep, at a depth of 11,000 meters. Appl. Environ. Microbiol. 64, 1510. https://doi.org/10.1128/AEM.64.4.1510-1513.1998 (1998).

8. Simonato, F. et al. Piezophilic adaptation: a genomic point of view. J. Biotechnol. 126, 11-25. https://doi.org/10.1016/j.jbiotec.2006. 03.038 (2006).

9. Cao, H. et al. Delta-proteobacterial SAR324 group in hydrothermal plumes on the South Mid-Atlantic Ridge. Sci. Rep. 6, 22842. https://doi.org/10.1038/srep22842 (2016).

10. Xiong, F. et al. Screening of marine fungi with antibacterial and antitumor activities from deep-sea sediments. J. Xiamen Univ (Nat Sci.) 45, 419-423 (2006).

11. Rosario, N. \& Antonio, T. Bioactive compounds produced by strains of Penicillium and Talaromyces of marine origin. Mar. Drugs 14, 37-41. https://doi.org/10.3390/md14020037 (2016).

12. Kaleem, A. et al. Phosphorylated and O-GlcNAc modified IRS-1 (Ser1101) and -2 (Ser1149) contribute to human diabetes type II. Protein Pept. Lett. https://doi.org/10.2174/0929866527666200813210407 (2020).

13. Takami, H., Inoue, A., Fuji, F. \& Horikoshi, K. Microbial flora in the deepest sea mud of the Mariana Trench. FEMS Microbiol. Lett. 152, 279-285. https://doi.org/10.1111/j.1574-6968.1997.tb10440.x (1997).

14. Zhang, X., Li, Y., Yu, Z., Liang, X. \& Qi, S. Phylogenetic diversity and bioactivity of culturable deep-sea-derived fungi from Okinawa Trough. J. Oceanol. Limnol. 4, 30. https://doi.org/10.1007/s00343-020-0003-z (2020).

15. Burgaud, G., Calvez, T. L., Arzur, D. \& Vandenkoornhuyse, P. Diversity of culturable marine filamentous fungi from deep-sea hydrothermal vents. Environ. Microbiol. 11, 1588-1600. https://doi.org/10.1111/j.1462-2920.2009.01886.x (2010).

16. Raghukumar, C., Muraleedharan, U., Gaud, V. R. \& Mishra, R. Xylanases of marine fungi of potential use for biobleaching of paper pulp. J. Ind. Microbiol. Biotechnol. 31, 433-441. https://doi.org/10.1007/s10295-004-0165-2 (2004).

17. Wang, Z. P. et al. Fungal community analysis in seawater of the Mariana Trench as estimated by Illumina HiSeq. RSC Adv. 9, 6956-6964. https://doi.org/10.1039/C8RA10142F (2019).

18. Raghukumar, C., Damare, S. \& Singh, P. A review on deep-sea fungi: occurrence, diversity and adaptations. Bot. Mar. 53, 479-492. https://doi.org/10.1515/bot.2010.076 (2010).

19. Daletos, G. et al. Natural products from Deep-Sea-Derived fungi-a new source of novel bioactive compounds?. Curr. Med. Chem. 25, 186-207. https://doi.org/10.2174/0929867324666170314150121 (2018).

20. Wang, Y. N., Meng, L. H. \& Wang, B. G. Progress in research on bioactive secondary metabolites from Deep-Sea derived microorganisms. Mar. Drugs 18, 614. https://doi.org/10.3390/md18120614 (2020).

21. Singh, P, Raghukumar C, Verma P, et al. Phylogenetic diversity of culturable fungi from the deep-sea sediments of the Central Indian Basin and their growth characteristics. Fungal Divers. 40(1), 89-102 https://doi.org/10.1007/s13225-009-0009-5 (2010).

22. Damare, V. \& Raghukumar, S. Morphology and physiology of the marine straminipilan fungi, the aplanochytrids isolated from the equatorial Indian Ocean. Indian J. Mar. Sci. 35, 326-340 (2006).

23. White, T. J. et al. Amplification and direct sequencing of fungal ribosomal RNA genes for phylogenetics in PCR protocols. 315-322 (Academic Press, Inc, 1990).

24. Zhang, X. et al. Insights into deep-sea sediment fungal communities from the East Indian ocean using targeted environmental sequencing combined with traditional cultivation. PLOS ONE https://doi.org/10.1371/journal.pone.0109118 (2014). 
25. Singh, P. et al. Fungal community analysis in the deep-sea sediments of the central Indian Basin by culture-independent approach. Microb. Ecol. 61(3), 507-517. https://doi.org/10.1007/s00248-010-9765-82011 (2011).

26. Wang, Y. T., Xue, Y. R. \& Liu, C. H. A brief review of bioactive metabolites derived from Deep-Sea fungi. Mar. Drugs 13, 4594-4616. https://doi.org/10.3390/md13084594 (2015).

27. Scott Chialvo, C. H., Griffin, L. H., Reed, L. K. \& Ciesla, L. Exhaustive extraction of cyclopeptides from Amanita phalloides: guidelines for working with complex mixtures of secondary metabolites. Nat. Ecol. Evol. https://doi.org/10.1002/ece3.6191 (2020).

28. Liu, J. et al. Proliferation of hydrocarbon-degrading microbes at the bottom of the Mariana Trench. Microbiome 7, 47. https://doi. org/10.1186/s40168-019-0652-3 (2019).

29. Peoples, L. M. et al. Microbial community diversity within sediments from two geographically separated Hadal Trenches. Front. Microbiol. 10, 347. https://doi.org/10.3389/fmicb.2019.00347 (2019).

30. Yang, C. L. et al. Introducing Arthrinium phyllostachium sp. nov. (Apiosporaceae, Xylariales) on Phyllostachys heteroclada from Sichuan province, China. Phytotaxa 406, 91-110. https://doi.org/10.11646/phytotaxa.406.2.2 (2019).

31. Ogaki, M. B. et al. Cultivable fungi present in deep-sea sediments of Antarctica: taxonomy, diversity, and bioprospecting of bioactive compounds. Extremophiles 24, 227-238. https://doi.org/10.1007/s00792-019-01148-x (2020).

32. Wang, W. et al. Cytotoxic nitrogenated azaphilones from the Deep-Sea-Derived fungus Chaetomium globosum MP4-S01-7. J. Nat. Prod. 83, 1157-1166. https://doi.org/10.1021/acs.jnatprod.9b01165 (2020).

33. Liu, R., Wang, L., Wei, Y. \& Fang, J. The hadal biosphere: Recent insights and new directions. Deep-Sea Res. Pt. II 155, 11-18. https://doi.org/10.1016/j.dsr2.2017.04.015 (2018).

34. Gao, Z. M. et al. In situ meta-omic insights into the community compositions and ecological roles of hadal microbes in the Mariana Trench. Environ. Microbiol. 21, 4092-4108. https://doi.org/10.1111/1462-2920.14759 (2019).

\section{Acknowledgements}

We would like to thank Shanghai Rainbowfish Company for providing the pathogenic bacteria strains used in this study. This work was supported by National Natural Science Foundation of China 42006086, Shanghai sailing program 20YF1416900, Shanghai Science and Technology Committee STCSM 20050501700, National Key R\&D Program of China (grant No. 2018YFC0310600), and the National Natural Science Foundation of China (91951210, 41773069).

\section{Author contributions}

Q.P. performed all experiments, analyzed the results and wrote the first draft of the manuscript. Y.L. and L.D. participated in performing the experiments. Y.L. analyzed the data about UPLC-MS. X.Y. designed, coordinated the study and wrote the manuscript. J.F. reviewed it and supervised the study. The manuscript was reviewed and approved by all authors.

\section{Competing interests}

The authors declare no competing interests.

\section{Additional information}

Supplementary Information The online version contains supplementary material available at https://doi.org/ 10.1038/s41598-021-90920-1.

Correspondence and requests for materials should be addressed to X.Y.

Reprints and permissions information is available at www.nature.com/reprints.

Publisher's note Springer Nature remains neutral with regard to jurisdictional claims in published maps and institutional affiliations.

(c) Open Access This article is licensed under a Creative Commons Attribution 4.0 International License, which permits use, sharing, adaptation, distribution and reproduction in any medium or format, as long as you give appropriate credit to the original author(s) and the source, provide a link to the Creative Commons licence, and indicate if changes were made. The images or other third party material in this article are included in the article's Creative Commons licence, unless indicated otherwise in a credit line to the material. If material is not included in the article's Creative Commons licence and your intended use is not permitted by statutory regulation or exceeds the permitted use, you will need to obtain permission directly from the copyright holder. To view a copy of this licence, visit http://creativecommons.org/licenses/by/4.0/.

(c) The Author(s) 2021 